\title{
Urban warming in Japanese cities and its relation to climate change monitoring
}

\author{
Fumiaki Fujibe \\ Meteorological Research Institute, Tsukuba 305-0052, Japan
}

\begin{abstract}
In Japan, most of the stations established by the beginning of the 20th century are located at cities, some of which have undergone rapid industrialization. The growth of large cities in Japan is accompanied by substantial increase of temperature, especially in the nighttime, while some large city regions show widespread warming in the daytime of the warm season. An attempt to separate urban warming and background temperature change has revealed anomalous trends not only in densely inhabited areas, but also only slightly urbanized sites with population density of $100-300 \mathrm{~km}^{-2}$. The effect of microscale climate changes on the observed temperature trend is also discussed.
\end{abstract}

Key words: urban warming, urban temperature, urban heat island, temperature trend, Japan, AMeDAS

\section{INTRODUCTION}

In Japan, there has been growing interest in urban warming, corresponding to the rapid development of cities. The warmth of large cities was already known to some climatologists before World War II. These studies were succeeded to the post-war period, in which high economical growth and industrial development resulted in serious environmental problems and advanced the interest in urban climates, not only for large cities but also for small towns and settlements (Yoshino, 1975; Kawamura, 1985). In the recent few decades, more attention has been paid to the summer heat load that is believed to be enhanced by the urban heat island, and the means to alleviate it from the viewpoint of urban planning. Today the phrase "heat island" is well known to people.

From the viewpoint of global warming, urban warming is regarded as a biasing factor in background climate monitoring, as many observatories having long history are located in cities (Karl et al., 1988; Jones et al., 1990). A number of studies emphasize the smallness of urban contribution in recent temperature data (Peterson, 2003; Peterson and Owen, 2005; Parker, 2006). In some other studies, however, urban warming has been found to have a substantial contribution to observed temperature changes (Jones et al., 2008; Ren et al., 2008; Lai and Cheng, 2009). The effect of microscale changes such as building construction and tree growth may also affect the analysis of climate change (Runnells and Oke, 2006; Pielke et al., 2007).

The presentation gives a brief review of urban climate studies in Japan, with focus on long-term urban warming. Detailed description of physical aspects of the urban atmosphere and modeling studies is found in reviews of Kanda (2007) and Kusaka (2008).

\section{MAIN FEATURES OF URBAN WARMING IN LARGE CITIES IN JAPAN}

The population of Japan has increased up to nearly four times of that in the middle of the 19th century, while the growth rate is still higher in a number of large cities. The population of Tokyo Metropolis, which includes the "ward area" (former Tokyo City, $621 \mathrm{~km}^{2}$ ) and its western suburbs, is about ten times of that in the 1870's. For the last few decades, the surrounding prefectures have rapidly developed as the population of Tokyo has almost saturated, corresponding to the expansion of the urban area.

The observatory of Tokyo, operated by the Japan Meteorological Agency (JMA), is located in the central business area of Tokyo since 1923 (Fig.1), in which it

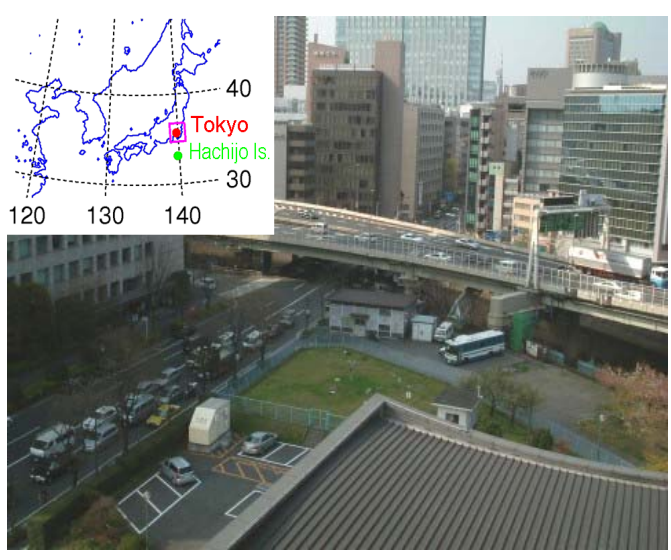

Fig.1 The observation site of Tokyo. The pink square in the map indicates the region shown in Fig.5.

Corresponding author: Fumiaki Fujibe, Meteorological Research Institute, Tsukuba 305-0052, Japan. E-mail:

ffujibe@mri-jma.go.jp. 
moved eastward by about $600 \mathrm{~m}$. Figure 2 shows the time series of daily mean temperature ( $\left.T_{\text {mean }}\right)$ at Tokyo and Hachijo Island, located $300 \mathrm{~km}$ south of Tokyo, together with Hadley Center's global average land temperature (CRUTEM3v, http://www.cru.uea.ac.uk/cru/data/temperatu re/). The linear trend of $T_{\text {mean }}$ at Tokyo is $3.00^{\circ} \mathrm{C} /$ century, which is more than a few times larger than that at Hachijo Island $\left(0.56^{\circ} \mathrm{C} /\right.$ century $)$, and also the global mean $\left(0.83^{\circ} \mathrm{C} /\right.$ century). The rate of increase is larger for daily minimum temperature $\left(T_{\min }\right)$ than for daily maximum temperature $\left(T_{\max }\right)$, so that the daily range has decreased. Rapid increases of temperature, especially of $T_{\mathrm{min}}$, are found for other large cities as well (Fujibe, 1995; JMA, 2005). As for seasonal variations, the warming of Japanese cities tends to be more conspicuous in cold seasons than in warm seasons.

Figure 3 shows the trends of $T_{\max }$ and $T_{\min }$ for 1891-1992 at 60 stations in Japan, with relation to the population $(P)$ of the cities or towns where they are located. There are positive correlations, with a larger value for $T_{\min }$, apart from large variabilities according to stations.

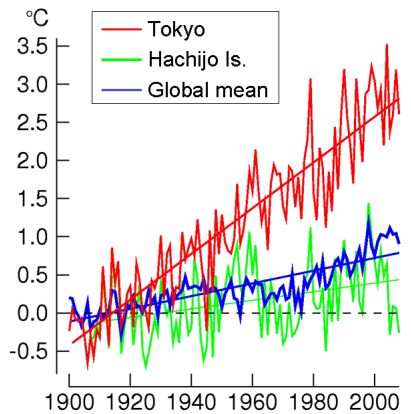

Fig.2 Time series of
annual mean temperature
for 1901 to 2008
(departure from the
average for $1901-1920$ ).
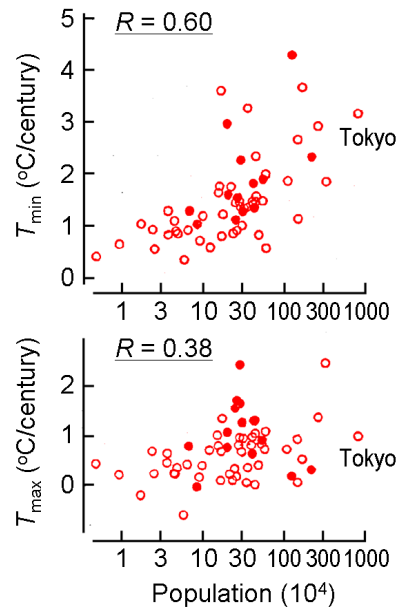

Fig.3 Relation between the linear trend of $T_{\text {min }}$ and $T_{\max }(1891-1992)$ and the population (in the 1990 census) of cities or towns where the stations are located (from Fujibe, 1995).

It is to be noted that increase of temperature and decrease of daily range have been found on the global scale (Karl et al., 1993), leaving uncertainty in the distinction of urban and global signals in observed trends. Separation of urban and background trends is discussed in section 4 from the viewpoint of climate change monitoring.

\section{EXTENDED HEAT ISLAND IN THE WARM SEASON}

Since the 1990's, mesoscale numerical models have come into use for urban climate studies, by incorporating the parameterization of urban surface processes. The models applied to sunny summer conditions, in which heat islands develop in the presence of the "extended sea breeze" (Kondo, 1990), have revealed widespread urban-induced anomaly of daytime temperature around Tokyo (Kimura and Takahashi, 1991; Kusaka et al., 2000; JMA, 2005; Fig.4), as a result of enhanced sensible heat due to reduced evapotranspiration over urban surfaces spreading for tens of kilometers. Correspondingly, $T_{\max }$ in the warm season is found to have increased from the vicinity of Tokyo to the northwestern corner of the Kanto plain (Fig.5). This feature, sometimes called the "extended heat island", has a much larger horizontal dimension than the traditional heat island confined to a single city. The extended heat island is characterized by the mixing layer with a height of $\sim 1 \mathrm{~km}$, so that the anomalous heat contained in the lower atmosphere is much larger than that of a nocturnal heat island. This heat content explains an increase of the amount of daytime pressure fall in Tokyo and the inland area at a rate of $\sim 0.3 \mathrm{hPa} /(30$ years) (Fujibe, 1994, 2003), which corresponds to a mixing height of several hundred meters according to the hydrostatic equation applied to the warming of $1^{\circ} \mathrm{C} /(30$ years).

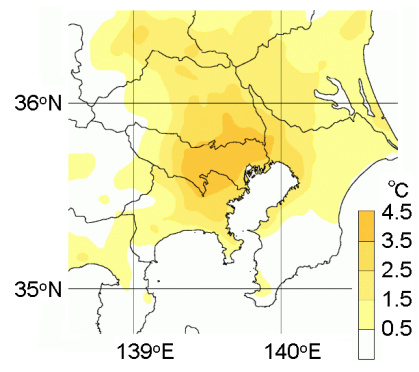

Fig.4 Difference of 14 JST surface air temperature in $4 \mathrm{~km}$-mesh simulations, with and without urban effects (anthropogenic heat and land use), for a sunny day in summer (from JMA, 2005).

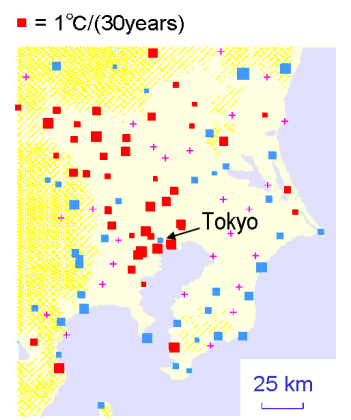

Fig.5 Linear trend of daily maximum temperature in the warm season (April to September) from 1946 to 1976. Positive and negative changes are shown in red and blue squares, respectively, with their area proportional to the magnitude of the trend (from Fujibe, 1994). 
The existence of extended heat islands is also reported for other large city regions (e.g., Kitada et al., 1998). It requires further research in order to quantify their contribution to long-term temperature trends.

\section{URBAN WARMING IN CLIMATE CHANGE MONITORING}

The monitoring of temperature changes of the background field requires data unaffected by urbanization. However, previous studies have shown that a heat island can be observed even in a small settlement with population of a thousand of less (Oke, 1973; Sakakibara and Matsui, 2005). The problem is whether such anomaly causes unnegligible bias in long-term averages and trends. The JMA uses temperature data at 17 stations for evaluating the climate change over Japan. These stations are "considered not to had been much influenced by urbanization", but "the analysis does not entirely eliminate the influence of urbanization". Indeed, some of the stations are in cities with population over a hundred thousand people.

Figure 6 shows the relation between the trends of daily mean temperature ( $T_{\text {mean }}$ ) and the population density in the surrounding area $(D)$, using data on the network of AMeDAS (Automated Meteorological Data Acquisition System) for March 1979 to February 2008. The procedure of analysis is the same as that of Fujibe (2008), except the data period has been extended for two years. There is a trend of about $0.3^{\circ} \mathrm{C} /$ decade even for stations with $D<100 \mathrm{~km}^{-2}$, indicating the background climate change. On the other hand, there is a positive correlation of 0.403 between the trend and $D$, indicating anomalous warming that is more rapid at stations with denser population.

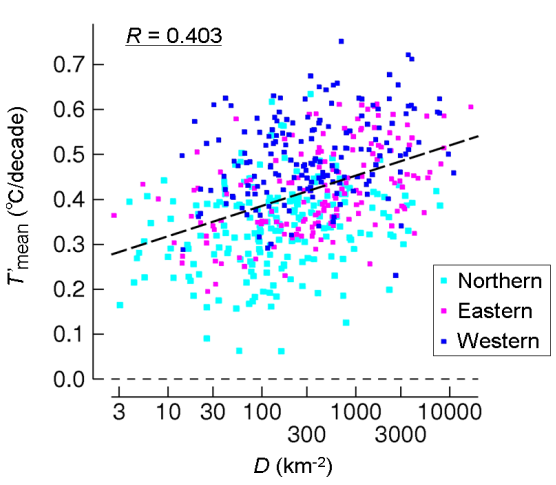

Fig.6 Plot of $\log D$ and $T_{\text {mean }}$ (Mar. 1979-Feb. 2008) at each station, colored according to regions. The gray dashed line indicates the linear regression for all the stations.

Figure 7 shows the anomalous trend with reference to rural sites, hereafter denoted by $\delta T^{\prime}$, defined by the trend of temperature deviation from its spatial average over $D<100 \mathrm{~km}^{-2}$ stations. It can be seen that stations in densely inhabited area $\left(D \geq 3000 \mathrm{~km}^{-2}\right)$ have an anomalous trend of $0.12^{\circ} \mathrm{C} /$ decade, which is close to the value estimated for Chinese cities (Jones et al., 2008; Ren et al., 2008). Moreover, an anomalous trend of $0.03-0.05^{\circ} \mathrm{C} / \mathrm{decade}$ is detected even for stations with $D=100-300 \mathrm{~km}^{-2}$. The time-of-the-day dependence of $\delta T^{\prime}(\mathrm{Fig}, 8)$ indicates a larger urban anomaly in the nighttime than in the daytime for densely inhabited area $\left(D \geq 1000 \mathrm{~km}^{-2}\right)$, in agreement with the general feature of the urban heat island. On the other hand, stations with relatively sparse inhabitants $\left(D=100-1000 \mathrm{~km}^{-2}\right)$ have double peaks in the morning and evening.

\section{MICROSCALE EFFECTS FOR OBSERVED TEMPERATURE CHANGE}

There are a variety of microscale factors that may affect long-term temperature trends (Pielke et al., 2007). Kondo (http://www.asahi-net.or.jp/ rk7j-kndu/) documented the temperature changes associated with those of wind speed at some stations in Japan, apparently as a result of changing

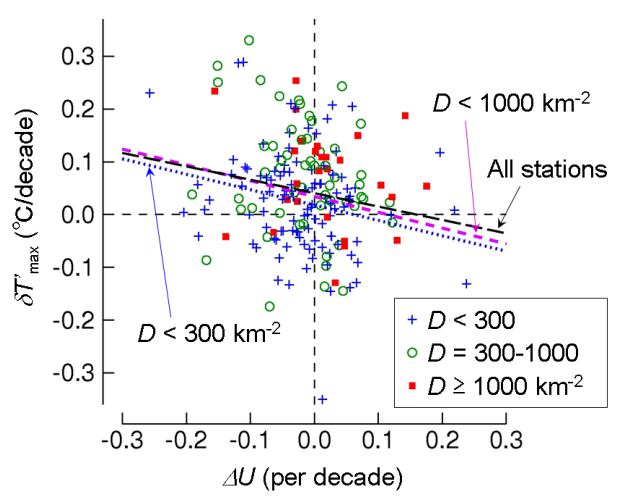

Fig.9 Relation between $\delta T_{\text {max }}^{\prime}$ and $\Delta U$ for stations with mean wind speed of $1.5 \mathrm{~m} / \mathrm{s}$ or more (From Fujibe, 2009). 
exposure that controls ventilation and vertical heat diffusion. Analysis for AMeDAS stations indicates rather complicated relationship between wind speed trends $(\Delta U)$ and temperature trends, depending on the mean wind speed of the site and time of the day (Fujibe, 2009; Fig.9). It will be a subject of future studies to quantify the processes of microscale temperature changes based on observation and numerical experiments.

\section{References}

Fujibe, F., 1994. Long-term falling trends of pressure over the Kanto plain as evidence of increasing heat content in the lower atmosphere in the daytime of the warm season, J. Meteorol. Soc. Jpn., 72, 785-792.

Fujibe, F., 1995. Temperature rising trends at Japanese cities during the last hundred years and their relationship with population, population increasing rates and daily temperature ranges, Pap. Meteorol. Geophys., 46, 35-55.

Fujibe, F., 2003. Long-term surface wind changes in the Tokyo metropolitan area in the afternoon of sunny days in the warm season, J. Meteorol. Soc. of Jpn., 81, 141-149.

Fujibe, F., 2008. Detection of urban warming in recent temperature trends in Japan, Int. J. Climatol., Early View, doi: $10.1002 /$ joc. 1822 .

Fujibe, F., 2009. Relation between long-term temperature and wind speed trends at surface observation stations in Japan, SOLA, 81-84.

Japan Meteorological Agency, 2005: Report on recent climatic change in the world 2005, 374pp. (in Japanese)

Jones, P. D., Groisman, P. Ya., Coughlan, M., Plummer, N., Wang, W.-C., Karl, T. R., 1990. Assessment of urbanization effects in time series of surface air temperature over land, Nature, 347, 169-172.

Jones, P. D., Lister, D. H., Li, Q., 2008. Urbanization effects in large-scale temperature records, with an emphasis on China, J. Geophys. Res., 113, D16122, doi:10.1029/2008JD009916.

Kanda, M., 2007. Progress in urban meteorology :A review, J. Meteorol. Soc. Jpn., 85B, 363-383.

Karl, T. R., Diaz, H. F., Kukla, G., 1988. Urbanization: its detection and effect in the United States climate record, J. Climate, 1, 1099-1123.

Karl, T. R., Jones, P. D., Knight, R. W., Kukla, G., Plummer, N., Razuvayef, V., Gallo, K. P., Lindseay, J., Charlson, R. J., Peterson, T. C., 1993. A new perspective on recent global warming: Asymmetric trends of daily maximum and minimum temperature, Bull. Am. Meteorol. Soc., 74, 1007-1023.

Kawamura, T., 1985. Recent changes of atmospheric environment in Tokyo and its surrounding area, Geogr. Rev. Jpn., B58, 83-94.

Kimura, F., Takahashi, S., 1991. The effects of land-use and anthropogenic heating on the surface temperature in the Tokyo Metropolitan area: A numerical experiment, Atm. Environ., 25B, 155-164.

Kitada, T., Okamura, K., Tanaka, S., 1998. Effects of topography and urbanization on local winds and thermal environment in the Nohbi Plain, coastal region of central Japan: A numerical analysis by mesoscale meteorological model with a $k-\varepsilon$ turbulence model, J. Appl. Meteorol., 37, 1026-1046.

Kondo, H., 1990. A numerical experiment of the "extended sea breeze" over the Kanto Plain, J. Meteorol. Soc. Jpn., $68,419-434$

Kusaka, H., 2008. Recent progress on urban climate study in Japan, Geogr. Rev. Jpn., 81, 361-374.

Kusaka, H., Kimura, F., Hirakuchi, H., Mizutori, M., 2000. The effects of land-use alteration on the sea breeze and daytime heat island in the Tokyo Metropolitan area, J. Meteorol. Soc. Jpn., 78, 405-420.

Lai, W.-L., Cheng, W.-L., 2009. Air temperature change due to human activities in Taiwan for the past century, Int. J. Climatol., Early View, doi:10.1002/joc.1898.

Oke, T. R., 1973. City size and the urban heat island, Atm. Environ., 7, 769-779.

Parker, D. E., 2006. A demonstration that large-scale warming is not urban, J. Climate, 19, 2882-2895.

Peterson, T. C., 2003. Assessment of urban versus rural in situ surface temperatures in the contiguous United States: No difference found, J. Climate, 16, 2941-2959.

Peterson, T. C., Owen, T. W., 2005. Urban heat island assessment: Metadata are important, J. Climate, 18, 2637-2646.

Pielke, R. A., Davey, C. A., Niyogi, D., Fall, S., Steinweg-Woods, J., Hubbard, K., K. Lin, K., Cai, M., Lim, Y.-K., Li, $\mathrm{H}$., 2007. Unresolved issues with the assessment of multidecadal global land surface temperature trends, J. Geophys. Res., 112, D24S08, doi:10.1029/2006JD008229.

Ren, G. Y., Zhou, Y., Chu, Z., Zhou, J., Zhang, A., Guo, J., Liu, X., 2008. Urbanization effects on observed surface air temperature trends in North China, J. Climate, 21, 1333-1348.

Runnalls, K. E., Oke, T. R., 2006. A technique to detect microclimatic inhomogeneities in historical records of screen-level air temperature, J. Climate, 19, 959-978.

Sakakibara, Y., Matsui, E., 2005. Relation between heat island intensity and city size indices/urban canopy characteristics in settlements of Nagano basin, Japan, Geogr. Rev. Jpn., 78, 812-824.

Yoshino, Y. Y., 1975. Climate in a small area, University of Tokyo Press, 549pp. 